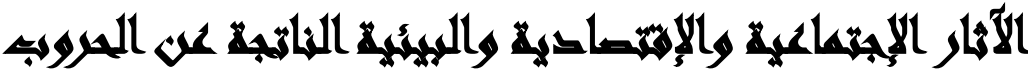

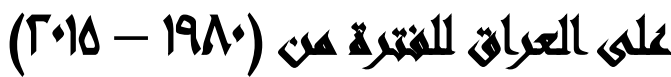

\section{$[1 \mathrm{lT}]$}

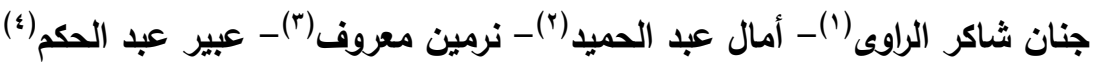

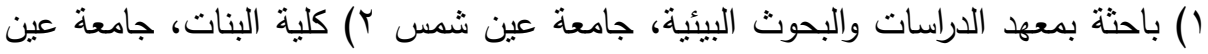

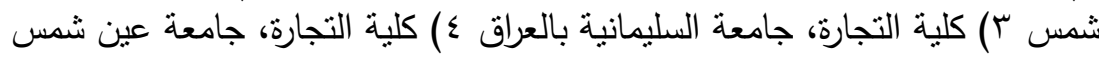

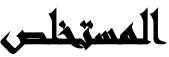

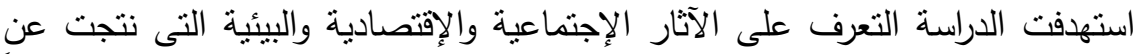
الحروب المتتالية على دولة العراق خلال حرب الخليج الأولى وحرب الخليج الثانية وأخيراً الغزو الأمريكى على العراق، واعتمدت الدراسة على استخدام المنهج الوصفى ولئ والتاريخى.

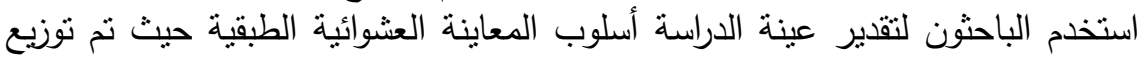

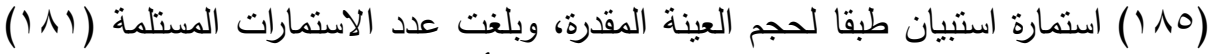

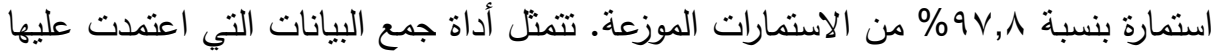

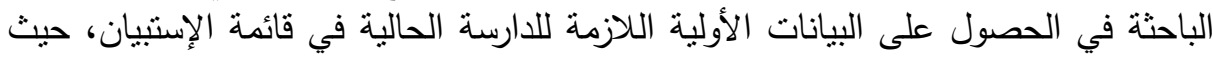

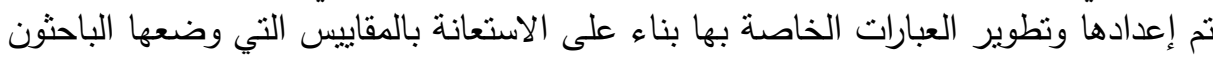

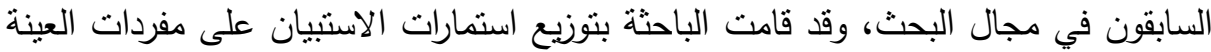

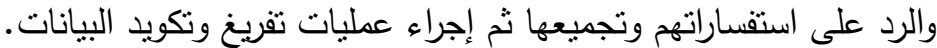

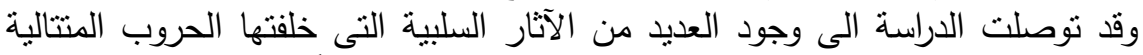

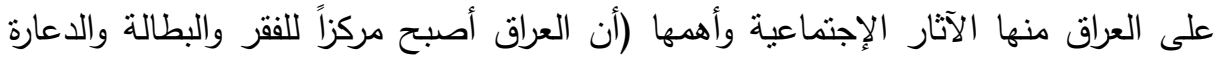

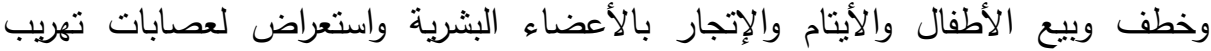

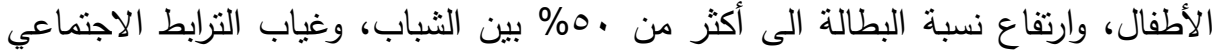

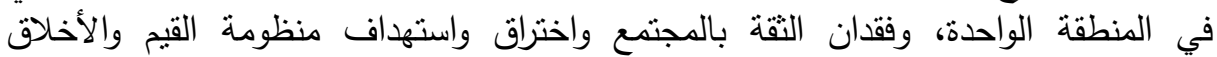

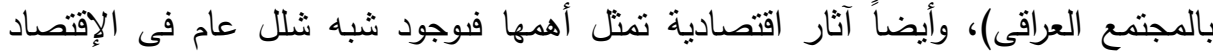

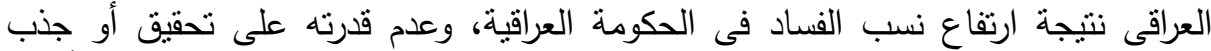

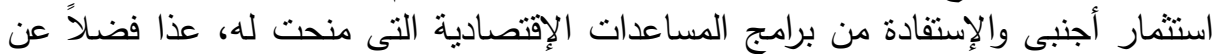

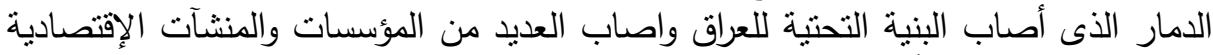

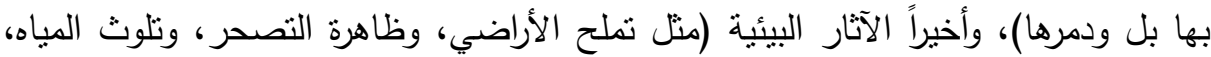

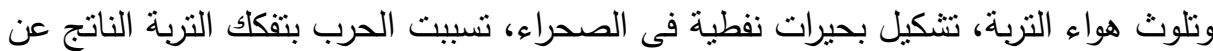
حفر الخنادق وزرع الألغام).

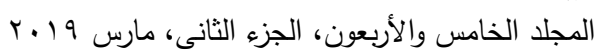


وقد أوصت الدراسة: بالعمل على نشر ثقافة السـام فى المجتمع الدولى وخاصة مناطق

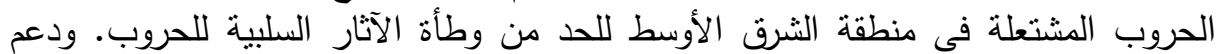

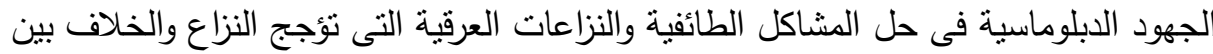

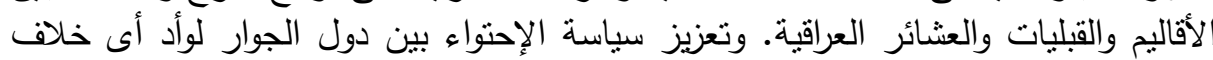

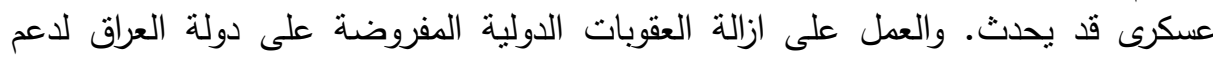

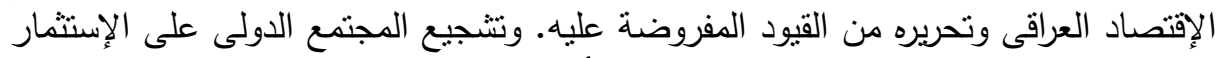

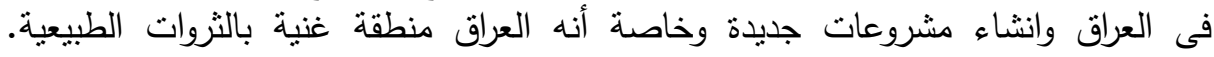

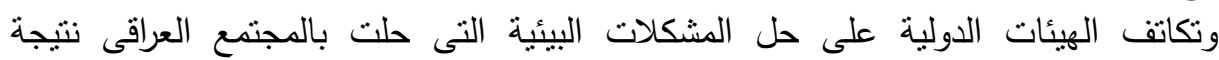

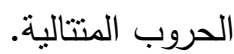

\section{Landill}

لم تكن الحروب والنزاعات الاهلية على مدى التاريخ إلا وبالاً وكارثة على الانسان،

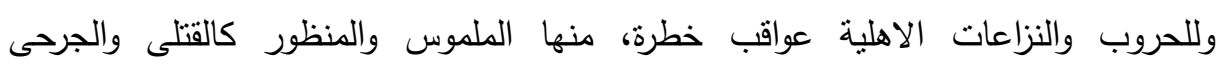

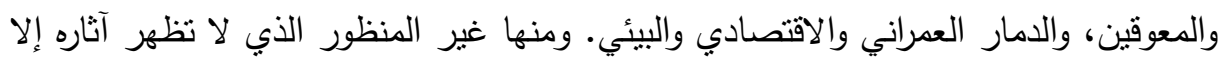

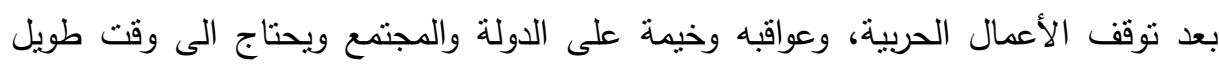

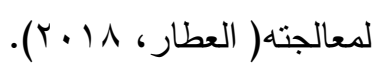

ولقد أصبح العراق محورا رئيسيا في المنافسة الإستراتيجية بين الولايات المتحدة وإيران،

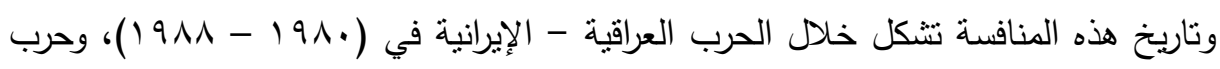

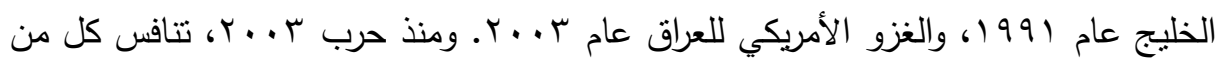
الولايات المتحدة وإيران على تشكيل هيكلة العراق لمرحلة ما بعد صدام حسين من ناحية السياسة، الحكم، الاقتصاد، والأمن (Dan Morse, 2011).

وسبيت الحروب والنزاعات المسلحة في العراق على مدى أربعين سنة فى ملايين

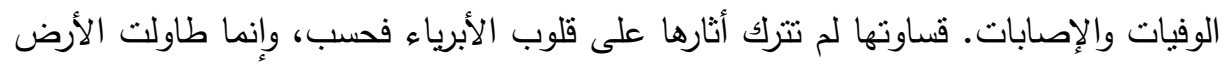

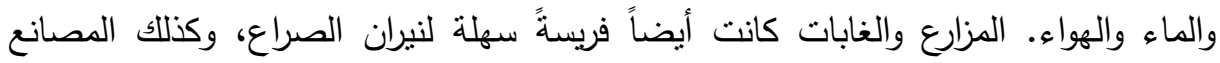
ومكامن النفط والثروات الطبيعية، التي أدى تدميرها إلى انتشار التلوث في كل مكان. وأنهكت الحروب المتتالية النظام الصحي في البلاد، وألحقت الضرر بالبنى النئى التحنية الأساسية، وأضعفت الإدارة البيئية والرقابة على المنشآت والفعاليات الصناعية. والخطط التي ولي ولئ 
وضعت بعد سنة r . . T لمعالجة هذه المشكلات لم تتجح في تحقيق أهدافها، لقلة الموارد

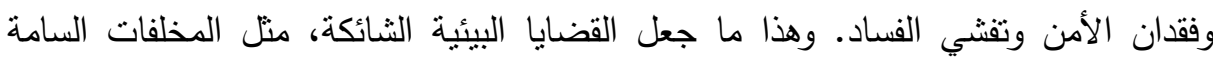
والمشعة والتلوث النفطي وفقدان الأراضي الزراعية، تنتراجع على سلم الأولويات وتنقى في هي

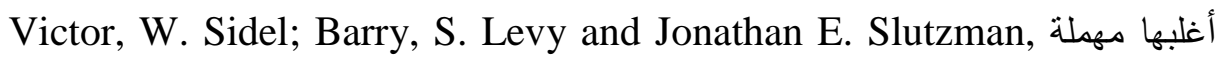
(2009 وحدد برنامج الأمم المتحدة الإنمائي في سنة ه . . ب ستين منطقة ساخنة تتطلب

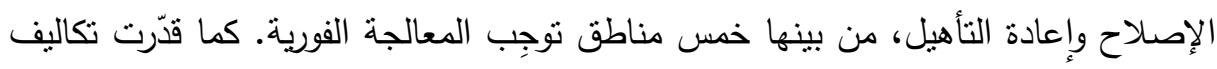

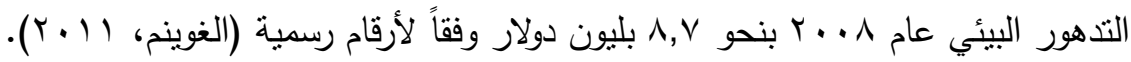

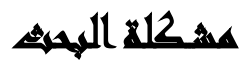

وفى ضوء ما نقدم وانطلاقاً من النتائج التى أسفرت عنها الدراسات والبحوث العلمية السابقة وما توصلت إليها الدراسات السابقة من حقائق، مثل:

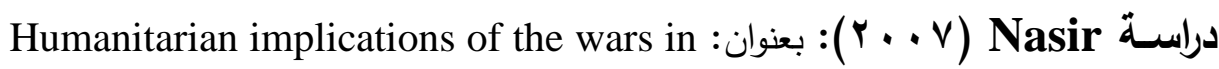
Iraq المجتمع العراقي، وتوصلت الى أنه "حرب على المدنيين" وأثر سلباً على معيشة ورفاهية

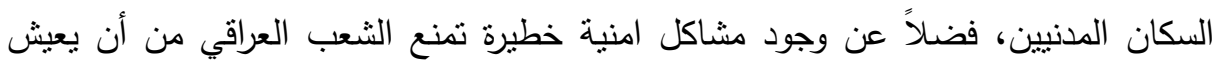

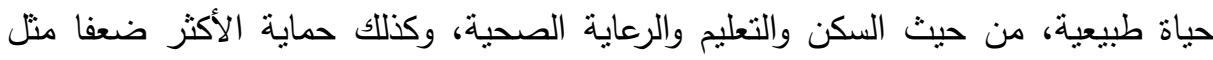
النساء والأطفال.

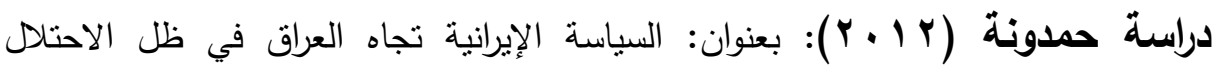

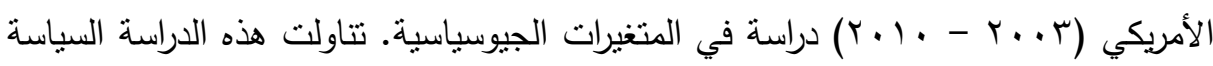

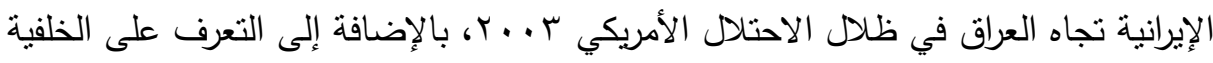

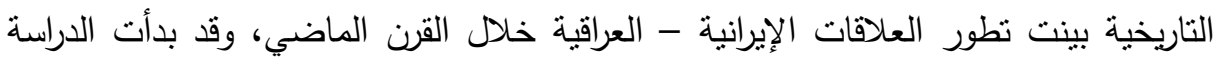

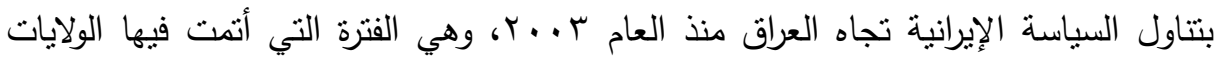
المتحدة الأمريكية احتلال العراق. 
خلصت الدراسة إلى أن الاحتلال الأمريكي للعراق شجع إيران لأن تلعب دوراً أكبر في تهري

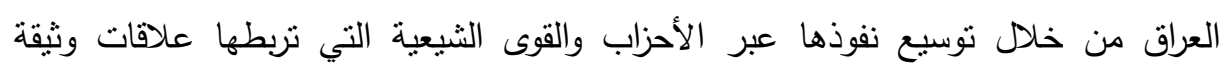

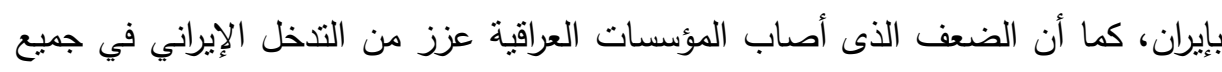

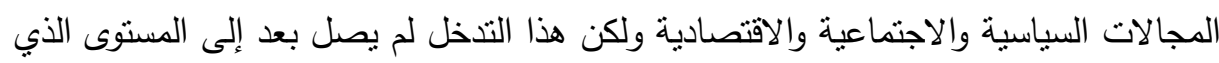
يتعارض مع المصالح الأمريكية.

لقد شهر اقتصاد العراقي في حقبة ثمانينات تراجعا كبيرا في ظل الحرب العراقية الايرانية وتركت الحرب اثارا كبيرة علي المجتمع من ناحية نفسية والاجتماعية والبيئية.

\section{أسئلة الترواسلة}

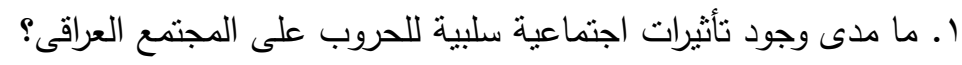

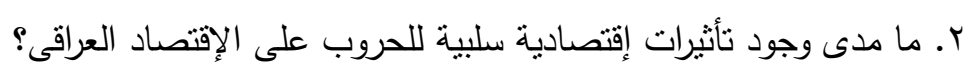

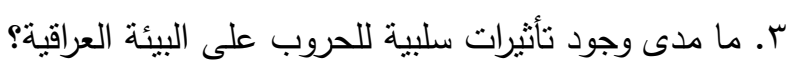

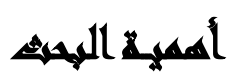

تتمحور أهمية الدراسة، هو زيادة المعرفة العلمية عن المجتمع العراقي على المستوي العلمي والتطبيقي. الأهمية العلمية: تتبع أهمية هذ البحث بإعتباره يناقش أحد الموضوعات الفكرية الحديثة،

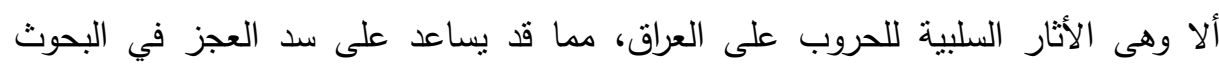

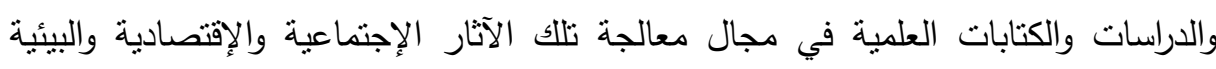

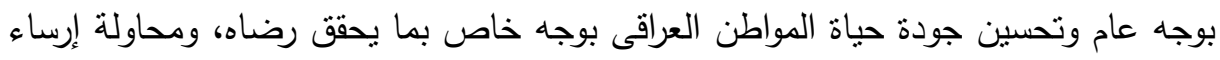

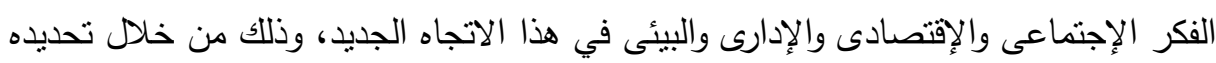

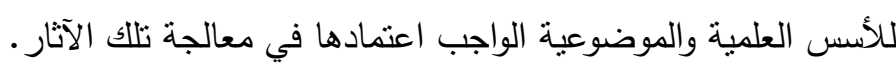

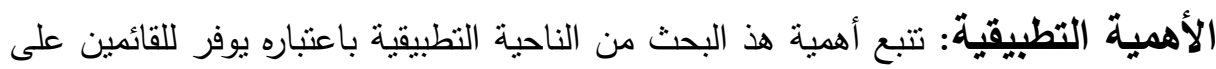

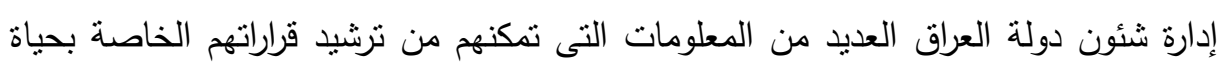

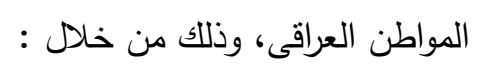


1-تقديمه دليلا علميا مبنياً على معلومات واقعية عن تحليل ومسيبات الآثار الإجتماعية

$$
\text { السلبية للحروب على العراق للمساعدة فى علاجها والحد من آثارها. }
$$

r-مساهمته في تفعيل النشاط الإقتصادى العراقى من خلال تحليل المؤشرات الإقتصادية فترة الدراسة واتباع الأساليب والحلول الإقتصادية لمعالجة آثار الحروب على لعالى العراق.

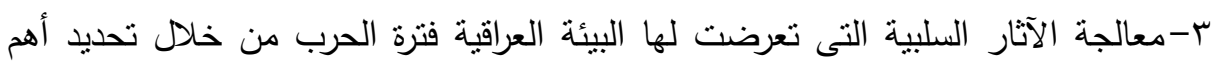
أنواع الأثار السلبية التى تعترى البيئة العراقية والوقوف على أهم طرق العلاج لتحسين لتعنية البيئة العراقية.

\section{أهساهن الهمهن}

1-التعرف على الآثار الإجتماعية للحروب على المجتمع العراقى فترة الدراسة وتحليل أهم

$$
\text { مسبباتها. }
$$

ץ-تحديد أهم الآثار الإقتصادية للحروب على الإقتصاد العراقى من خلال التعرف على أهم

$$
\text { المؤشرات الإقتصادية الخاصة بالإقتصاد العراقى وتطورها. }
$$

r-التعرف على الآثار البيئية للحروب على البيئة العراقية فنرة الدراسة وتحديد أنواعها.

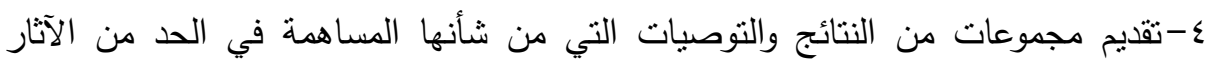
السلبية للحروب على العراق بما يحقق مصلحة المواطن العراقى.

\section{هنروض الهبه}

تحقيقا لأهداف الدراسة، فإن هذا البحث يقوم باختبار مدى صحة ثلاثة فروض أساسية كما يلي: الفرض الأول: لا توجد علاقة ذات دلالة إحصائية بين الآثار الإجتماعية على المجتمع

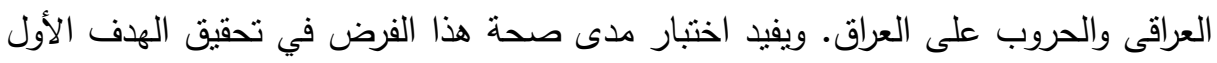

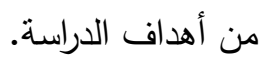

$$
\text { المجلد الخامس والأربعون، الجزء الثانى، مارس 19 ب r }
$$


الفرض الثاني: لا نوجد علاقة ذات دلالة إحصائية بين الآثار الإقتصادية على الإقتصاد

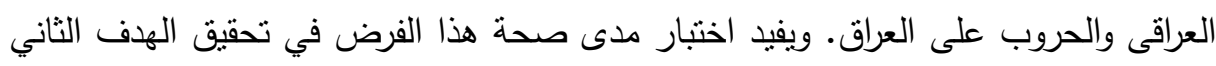
من أهداف الدراسة.

الفـرض الثالث: لا نوجد علاقة ذات دلالة إحصائية بين الآثار البيئية على البيئة العراقية

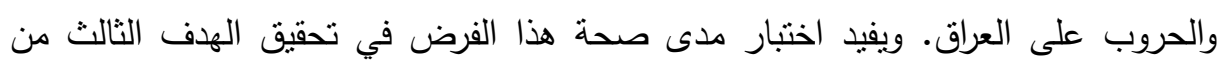
أهداف الدراسة.

\section{Anara}

تعد هذه الدراسة من الدراسات الوصفية التي تصف الجوانب المُختلفة من الأطروحة

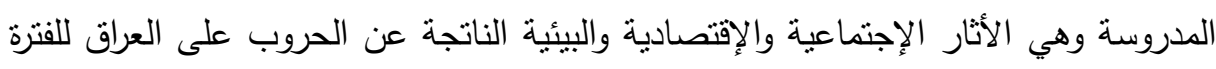

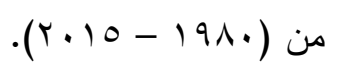
وقد استخدم الباحثن في هذه الدراسة المنهج التحليلي وتبرز أهمية هذا المنهج في نتاول

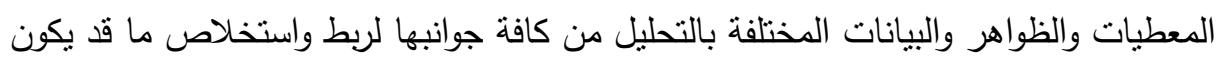
من علاقة قد تكثف عن حقائق محددة ما كان يمكن الوصول إليها بغير استخدام هذا المنهج

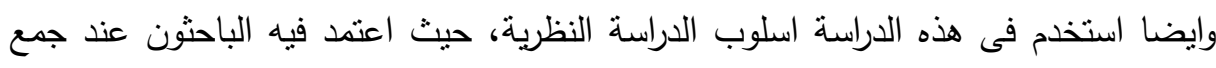
بيانات الإطار الفكري لهذه الدراسة على مجموعة من المراجع الأجنبية والعربية والبحوث

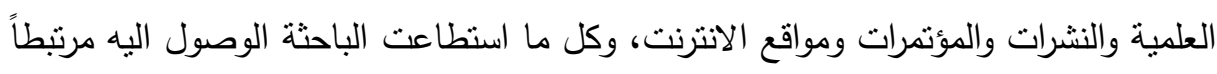
بمجال الدراس.

\section{Aبs}

يقتصر البحث على دراسة الآثار الإجتماعية والإقتصادية والبيئية للحروب على دولة

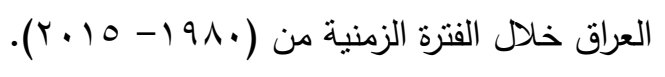




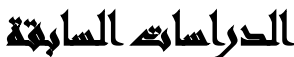

اهتمت العديد من البحوث والدراسات العلمية بموضوع الحروب بصفة عامة وفى دولة العراق وأثارها الإقتصادية والبيئية والإجتماعية، وفى هذا الجزء تستعرض الباحثة أهم الدراسات والبحوث العلمية التى نتاولت موضوع الحروب على العراق كما يلى:

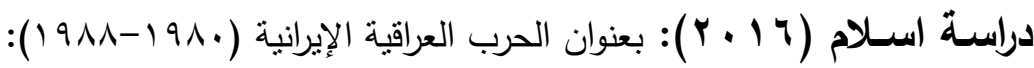

هدفت هذه الدراسة إلى توضيح أسباب العداء بين العراق وايران، وإلقاء الضوء على أهم الهم الهربه

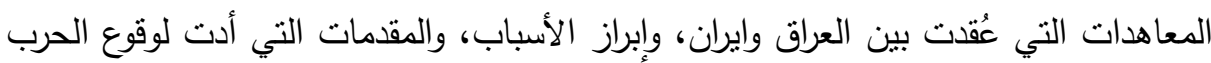
بين العراق وايران. وتوصلت الى أنه تعثرت عملية التتمية في العراق، كما ادت الحرب لركود القطاع الصناعي، والزراعي، كما تدمرت الكثير من المؤسسات الصناعية خلال الحرب، اضافة إلى نقص المواد الأولية والسلع، وعدم توفر قطع الغيار، والطاقة الكهربائية اللازمة لتتغيل

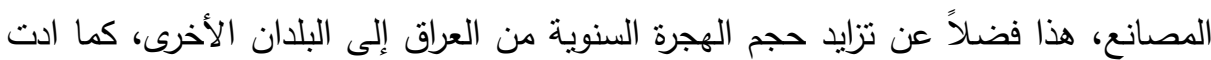

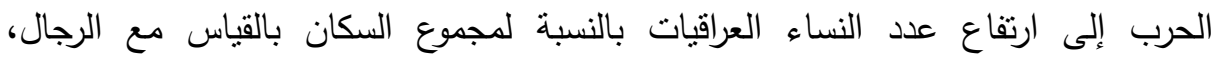
وبالمقارنة في السنوات التي سبقت الحرب. دراسة حمدى (0 1 • Y): بعنوان: انعكاسات الإستراتيجية الأمنية الإيرانية على دول الخليج

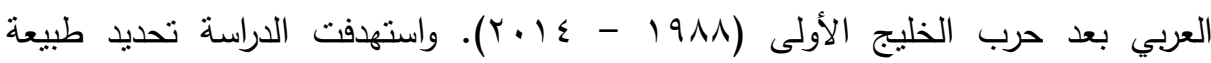
الإستراتيجية الأمنية الإيرانية اتجاه منطقة الخليج العربي، والتعرف على ملامح العلاقات

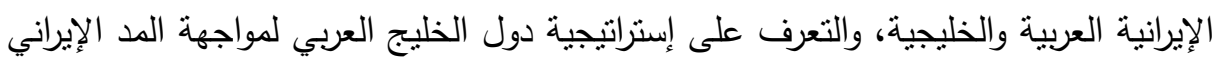
في المنطقة، وأهم مرتكزات السياسة الإيرانية في منطقة الخليج العربي. وتوصلت الى سعي إيران لامتلاك قوة عسكرية يجعلها تبرز في المنطقة كقوة إقليمية في

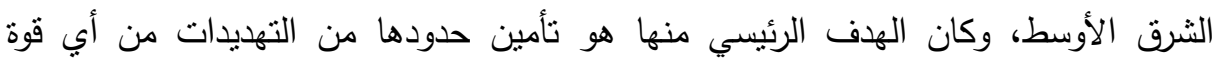

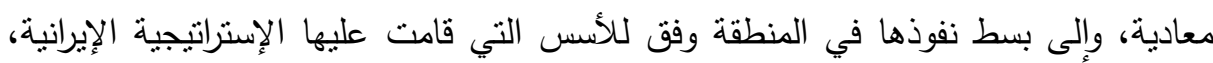

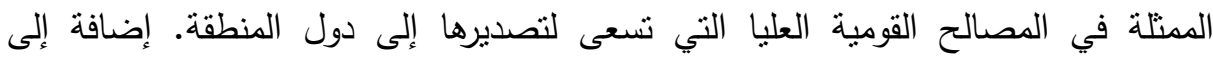


تداعيات المشروع النووي الإيراني على دول المنطقة وتأثيره على استقرار وأمن المنطقة وموقف القوى الكبرى من هذا المشروع.

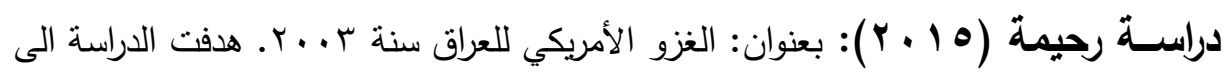
الكثف عن الإستراتيجية الأمريكية في الثرق الأوسط التي عملت على تحقيقها من خلال

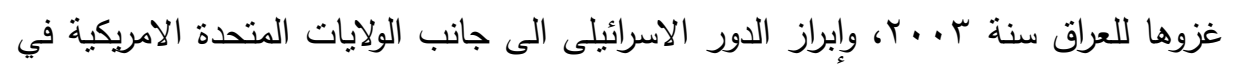

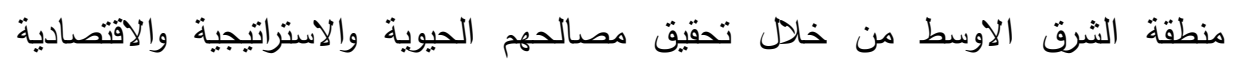
والسياسية في المنطقة من خلال عملية الغزو، ومعرفة الاثار والمواقف الدولية والاقليمية من السياسة الامريكية في العراق وأهم نتائجها سواء على الجانب العرقي او الامريكي.

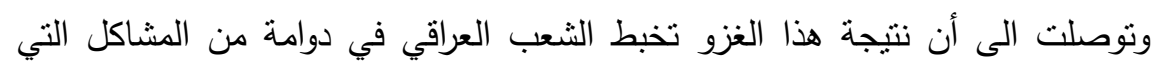

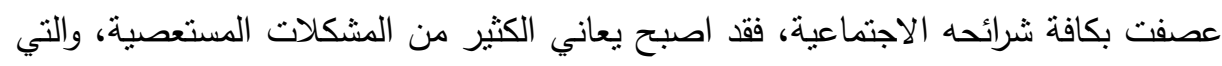

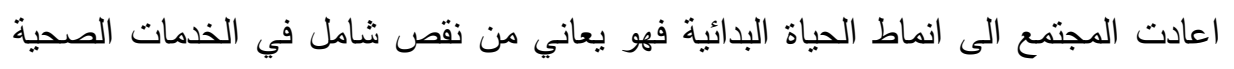

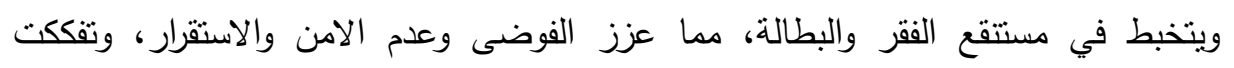

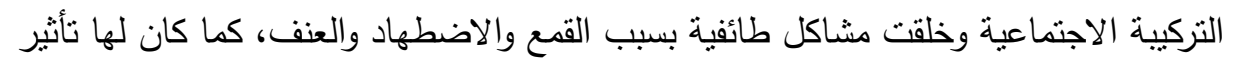

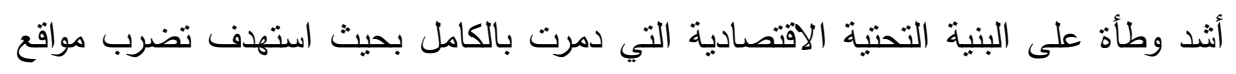

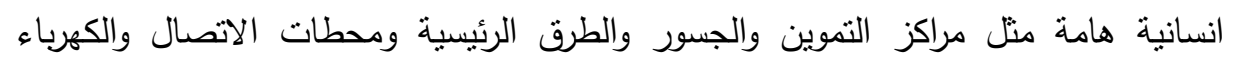
والمصانع المدنية والورش والمصانع الحربية، مما ادى الى انهيار العراق بشكل سريع.

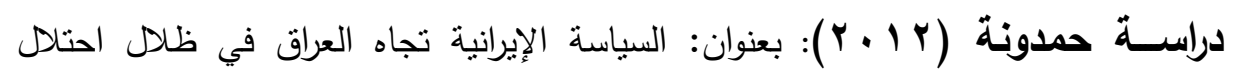

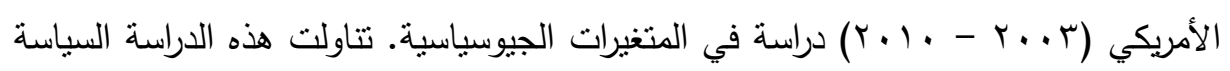

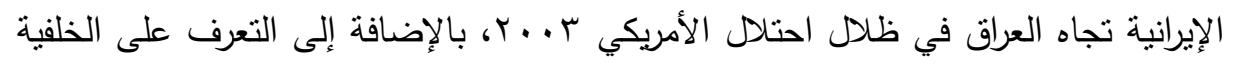

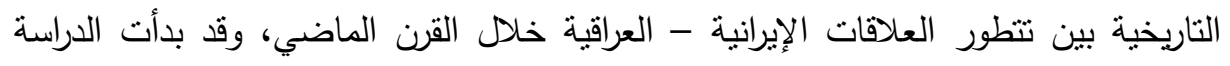

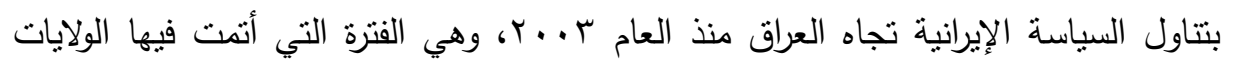
المتحدة الأمريكية احتلال العراق. خلصت الدراسة إلى أن الاحتلال الأمريكي للعراق شجع إيران لأن تلعب دوراً أكبر في

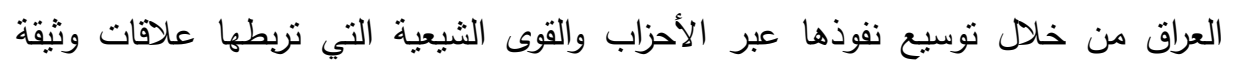
بإيران، كما أن الضعف الذى أصاب المؤسسات العراقية عزز من التدخل الإيراني في جميع 374

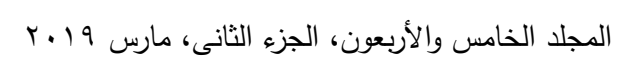


المجالات السياسية والاجتماعية والاقتصادية ولكن هذا التدخل لم يصل بعد إلى المستوى الذي يتعارض مع المصالح الأمريكية.

دراسـة (Dean Baker, 2009): بعنوان: The Economic Impact of the Iraq) War and Higher Military Spending

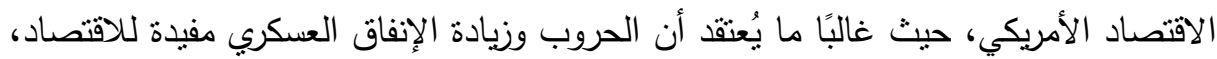

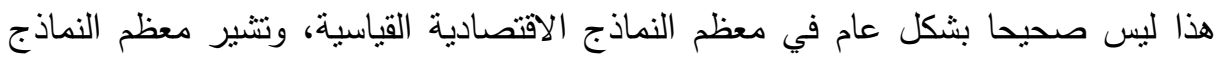

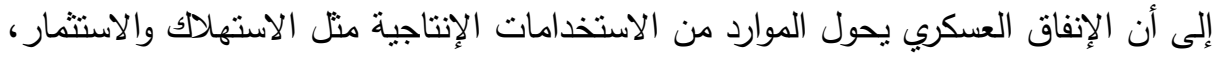
ويؤدي في النهاية إلى إيطاء النمو الاقتصادي ويقلل من فرص العمل. وقامت الدراسة باستخدام نموذج Global Insight وأوضحت محاكاة لأثر زيادة في

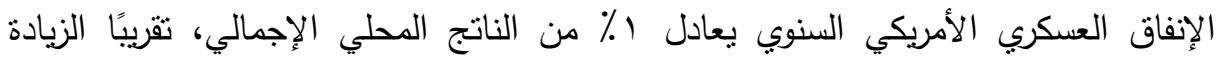

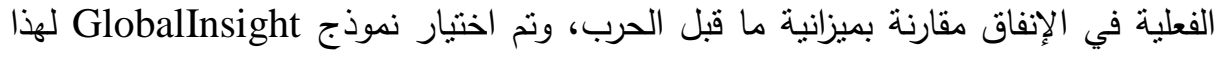
التحليل لأنه نموذج شائع الاستخدام ومحترم على نطاق واسع. وتوصل النموذج ايضاً الى لى مجموعة من التوقعات منها زيادة في الإنفاق العسكري السنوي يعادل ·, ال في المئة من الناتج

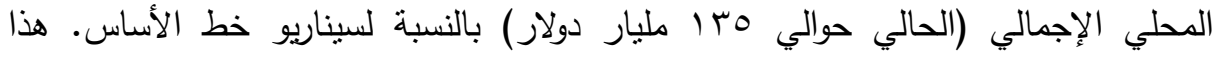

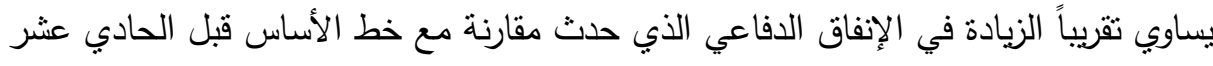
من سبتمبر •

دراسة (Nasir, 2007): بعنوان Humanitarian implications of the wars in Iraq المجنمع العراقي.

وتوصلت الى أنه "حرب على المدنيين" وأثز سلباً على معيثة ورفاهية السكان المدنيين،

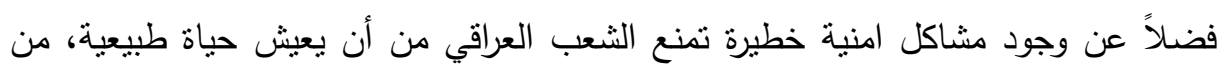
حيث السكن والتعليم والرعاية الصحية، وكذلك حماية الأكثر ضعفا منل النساء والأطفال. 
The Total Economic Costs of the War بعنسة (Charles, 2007): بعوان Beyond the Federal Budget العراق وأفغانستان على الولايات المتحدة والقوات المسلحة الأمريكية.

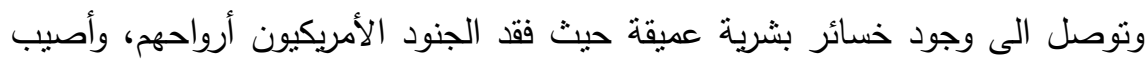

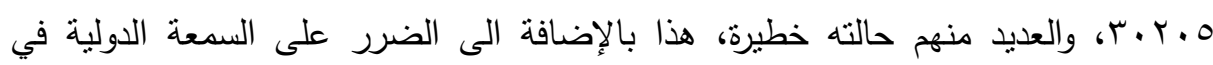

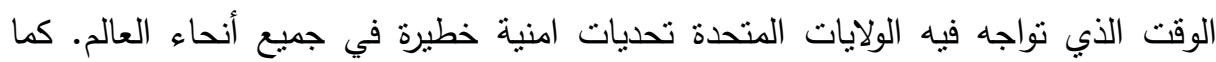
توصل التقرير الى تقدير إجمالي تكاليف الحرب الطويلة في العراق للاقتصاد الأمريكي ككل.

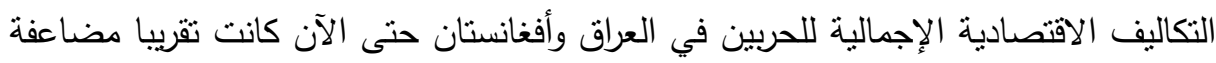

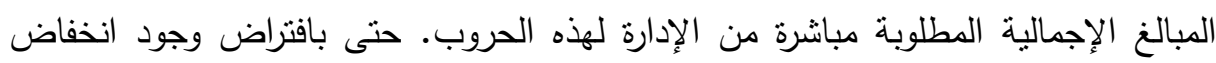

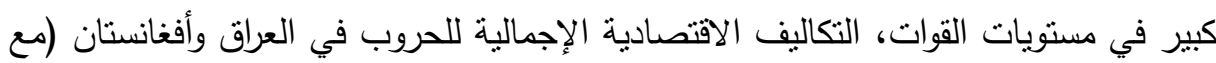

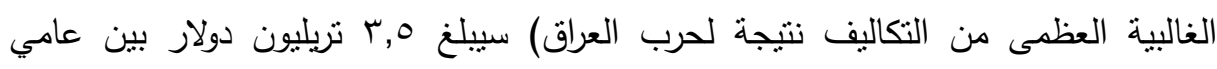

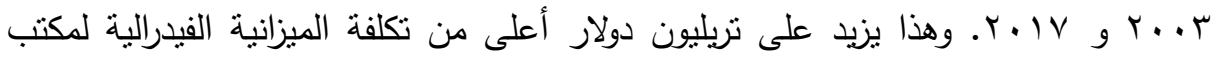

$$
\text { الكونجرس (CBO). }
$$

\section{تعقيب على الدراسات السابقة:}

ا ـ أن دراسة الآثار السلبية للحروب فى دول العالم بصفة عامة يكتسب أهية بالغة، وفى

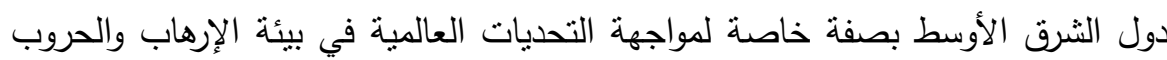

$$
\text { الدائرة فى المنطقة. }
$$

r. ركزت دراسات على الآثار الإجتماعية أو الإقتصادية أو البيئية للحروب بصفة منفصلة

$$
\text { لكل نوع من هذه الآثار على حده. }
$$

r. تركيز معظم الدراسات على الجانب الإقتصادى او الإجتماعى واغفال الجانب البيئى

$$
\text { لاحروب. }
$$

ع. الدراسات السابقة لم تركز على دراسة الآثار الإجتماعية والإقتصادية والبيئية للحروب على البى العراق مجتمعة وخلال الثلاثة فترات للحروب (حرب الخليج الأولى والثانية والثالثة).

$$
\text { المجلد الخامس والأربعون، الجزء الثانى، مارس } 9 \text { ـ أب }
$$




\section{الإسار النظلغيه للمهشه}

يشمل الدراسة الاثار الاجتماعية والاقتصادية والبيئية في الحروب التي خاضها العراق

من سنة .9191 الي سنة 10 ـ ب مع ايران، والحرب الخليج اولي، والحرب الخليج الثانية. الآثار الاجتماعية: تتمنل الحرب العراقية الايرانية بالعديد من الاثار سلبية التي خلفتها هذة الحرب، هي اعنف شكل من انكال الصراع فهذة الحرب تعتبر اطول الحرب إقليمية، ورغبة الاطراف المتحاربة في توسيع النطاق الحرب، ونتج عن ذلك زبج المدنين في كلا الدولتين بما

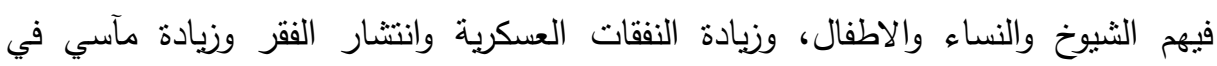
أدت الحرب العراقية - الإيرانية إلى مزيد من التعبئة السياسية في كلا الدولتين، ونتج

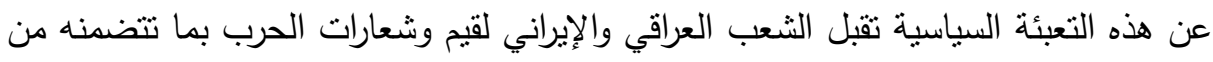
رغبة في التضحية والقتال، لتحقيق الأهداف القومية السامية، والتي حددتها القيادة السياسية العليا في كلا الدولتين. فقد أصبح شعار "حرب.... حرب حتى النصر" يتردد في أنحاء إيران والعراق وبشكل مألوف. وحيث أن ظروف الحرب توجد في معظم الأحيان تتاسقا تلقائياً بين

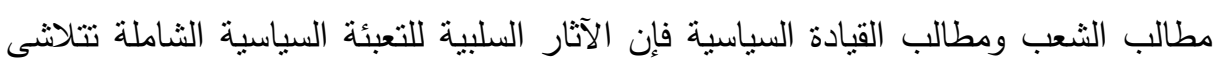
مرحليا خلال الحرب أمام الرغبة العامة لتحقيق الأهداف القومية السامية.

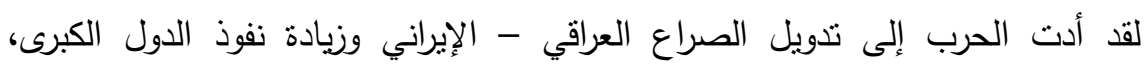

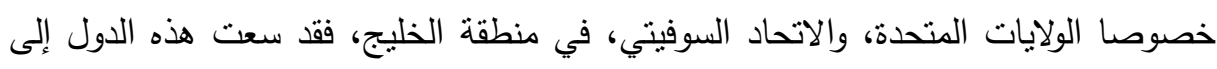
الاستفادة من الثغرات التي أوجدتها الحرب لتعزيز وجودها السياسي والعسكري في منطقة فئسة

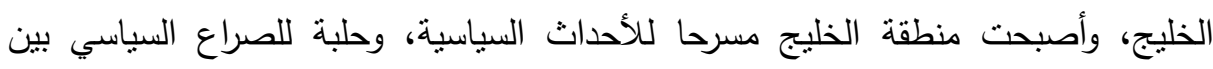
العملاقين، وميدانا لفحص أسلحتهما الحربية. الآثار الاقتصادية: يصعب حصر مجمل الاثار الاقتصادية للحروب، الا أنه من الواضح

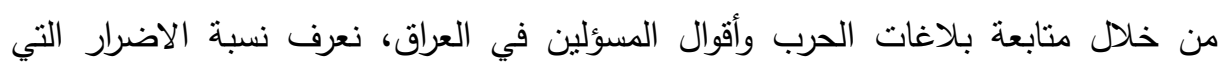

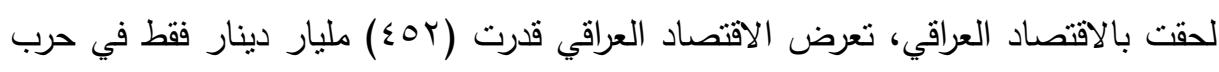

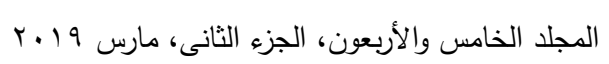


ايران بما يعادل • 1 اضعاف معدل النتاج المحلي. سحبت الحرب ما لدى طرفيها من احتياطي العملات الأجنبية، ودفعت أحدهما وهو العراق إلى دخول سوق المديونية الدولية.

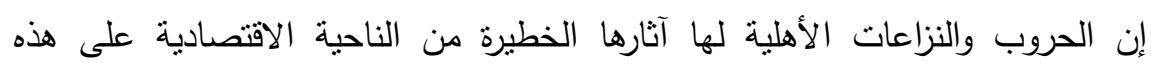
الدول، حيث تؤدي إلى توقف او ضعف حركة التتمية بسبب هروب الاستثمارات الداخلية ومنع تدفق الاستتمارات الأجنبية نظرا لإمكانية تدمير المنشآت الاقتصادية والبنى الأساسية

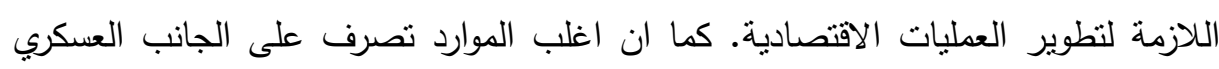

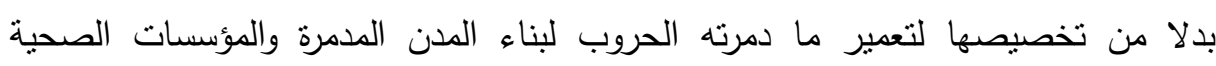
والتعليمية المنهارة.

الآثار البيئية: تعرضت البيئة في العراق بسبب الحرب ما لم يتعرض له البيئة في ابي بلدان

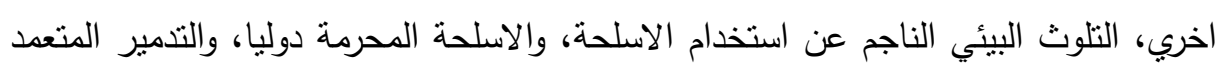

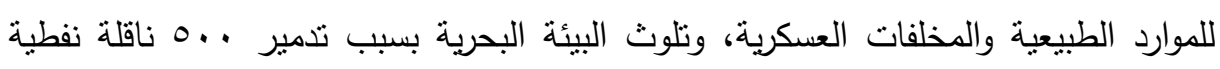
تجارية واستهداف منشآت النفط. وانهكت الحرب النظام الصحي في البلد والحقت الضرر بالاراضي الزراعية، وتلوثت التربة بالمخلفات السامة والمشعة وانتشار الامراض متل ولت سرطان

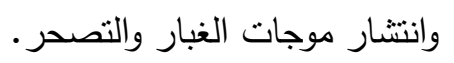
تلوث الهواء بسبب أنقاض البناء في مناطق الحروب لا يقتصر على الجسيمات الدقيقة

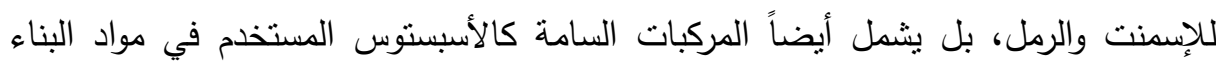
والمعادن الثقيلة الموجودة في طلاء الجدران، إلى جانب المواد الكيماوية الخطيرة التي تدخل

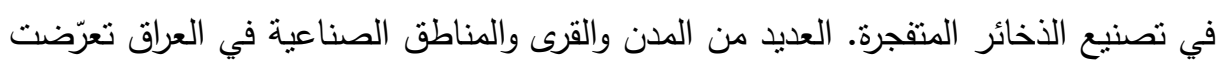
لأعمال حربية أدت إلى دمار واسع في أكثر من مكان.

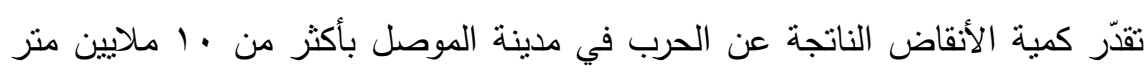

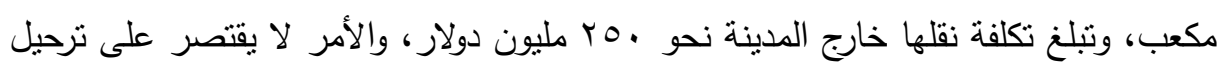

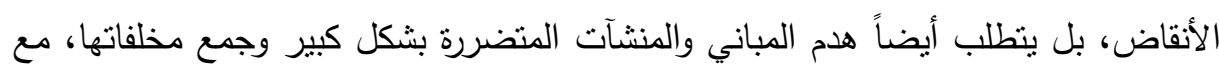
ما يستتبع ذلك من أخطار صحية وبيئية، بخاصة بوجود بعض الذخائر غير المنفجرة. 


\section{إجباءاهت القواسمة}

مجتمع الاراسـة: يتمثل مجتمع الدراسة في مجموعة الخبراء والمتخصصين والمهتمين وأساتذة الجامعات المتخصصين في علم الاجتماع والاقتصاد والعلوم البيئة.

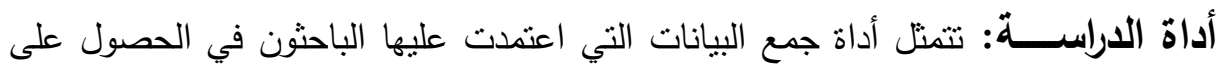

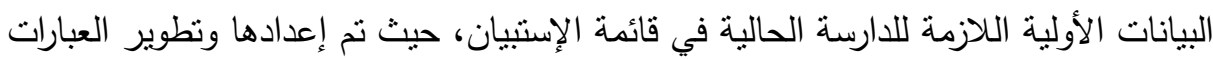

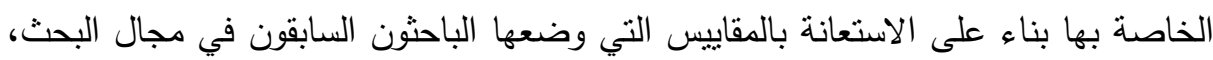

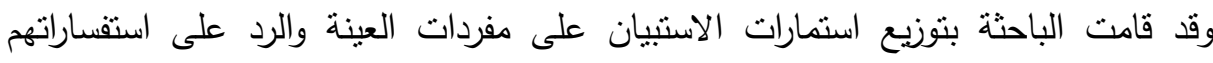

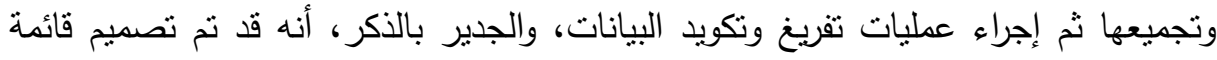

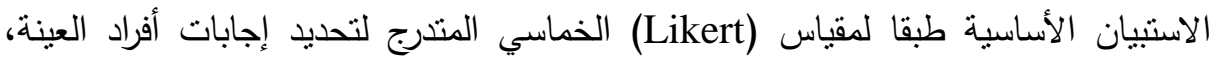

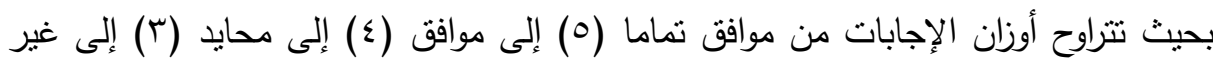

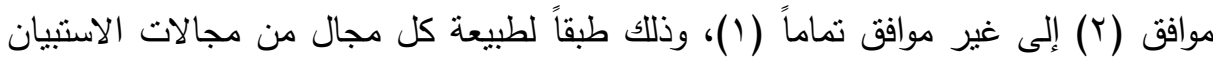

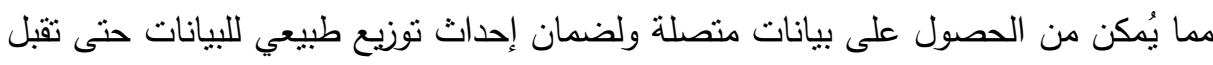
تطبيق الأساليب الإحصائية عليها. إجراءات بناء أداة الدراسـة (الاستبيان): الجزء الأول: وقد اشتمل على مجموعة من الأسئلة الديموغرافية التي تحدد بعض الخصائص التص التصائ

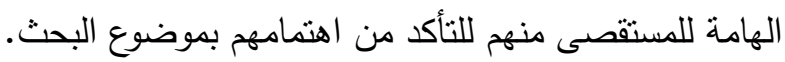
الجزيء الثاني: انقسم إلى ثلاث محاور أساسية على النحو النالي: الناعي:

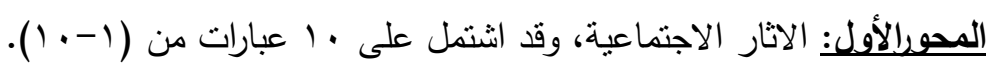

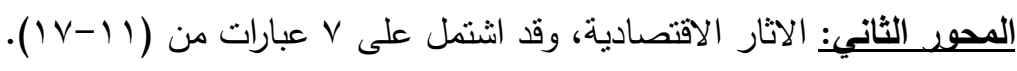

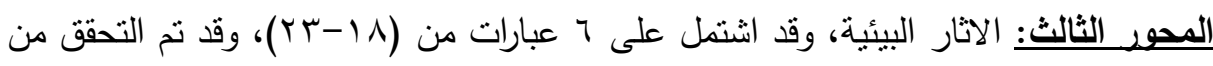

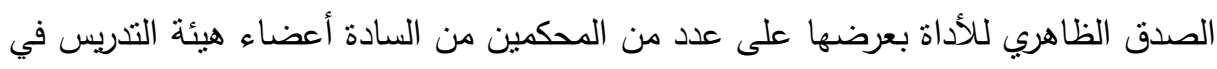

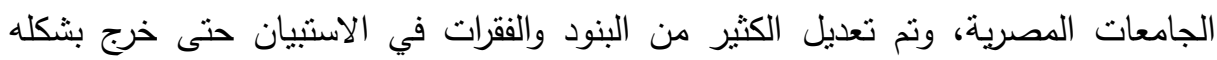

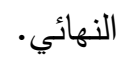

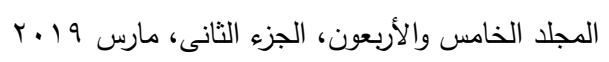




\section{اختبار الصدق والثبات لأداة الدراســة:}

صدق البناء الاخلي: وهو يقيس مدى تحقيق الأهداف التي تريد الأداة الوصول إليها من خلال إيجاد معامل الارتباط بين معدل كل محور و المعدل الكلي لفقرات الاستبيان، وبيين

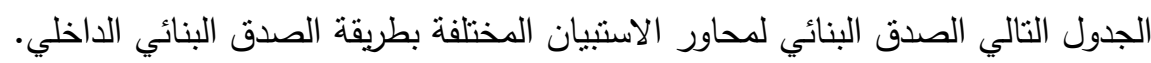
جدول (1): الصدق البنائي لمحاور الاستنيان المختلفة بطريقة الصدق البنائي الداخلي الإسي

\begin{tabular}{|c|c|c|}
\hline المعنوية & معامل الارتباط & محاور الاستبيان \\
\hline $\bar{a}, \ldots$ & $\cdot, V Y Y$ & الآثار الاجتماعية \\
\hline$\cdot, \cdots$ & $\cdot, \vee \vee 70$ & الآثار الاقتصادية \\
\hline$\cdot, \cdots$ & $\cdot, T \wedge Y$ & الآثار البيأُــية \\
\hline
\end{tabular}

وقد أظهرت نتائج الجدول السابق رقم (1) أن محتوى محاور الاستبيان لها علاقة ارتباط قوية بهدف الدراسة عند مستوى دلالة مرتفع المعنوية، مما يؤكد نوافر الصدق البنائي

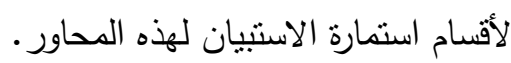
طريقة التجزئة النصفية Split-Half Coefficient: نم تقدير معامل ارتباط بيرسون بين معدل الأسئلة الفردية الرتبة ومعدل الأسئلة الزوجية الرتبة لكل محور وقد نم تصحيح معاملات

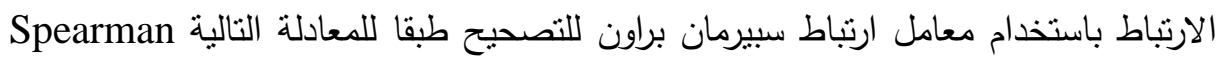

Brown Coefficient $2 \times r$

$$
\begin{aligned}
& \text { معامل الثبات = -----------_xi } \\
& r+1 \\
& \text { حيث (r) معامل الارتباط. }
\end{aligned}
$$

\begin{tabular}{|c|c|c|c|}
\hline المعنوية & معامل الثبات & معامل الارتباط & محاور الاستبيان \\
\hline$\cdot, \ldots$ & $\cdot, \wedge \leqslant \wedge$ & . & الآثار الاجتماعية \\
\hline$\cdot, \cdots$ & $\cdot, \wedge \ldots$ & ., 777 & الآثار الاقتصادية \\
\hline$\cdot, \cdots$ & •, А५ & $\cdot, V Y Y$ & الآثار البئُـية \\
\hline
\end{tabular}

ويوضح الجدول التالي ثنات فقرات محاور الاسنبيان بطريقة التجزئة النصفية. جدول (ץ): ثبات فقرات محاور الاستبيان بطريقة التجزئة النصفية 
ويوضح الجدول السابق رقم (Y) ثبات فقرات محاور الاستبيان بطريقة التجزئة النصفية، وقد جاءت النتائج لتؤكد أن محتوى محاور الاستبيان لها علاقة ارتباط قوية بهدف الدراسة عند مستوى دلالة مرتفع المعنوية، مما يؤكد توافر ثنات فقرات الاستبيان في أقسامه المختلفة. الصدق والثبات بطريقة ألفا كرونباخ: تم تقدير الصدق والثبات من خلال مقياس (ألفات بوات كرونباخ) فإذا زاد هذا المقياس عن • ب, •أمكن الاعتماد على نتائج الدراسة وتعميمها على عنى

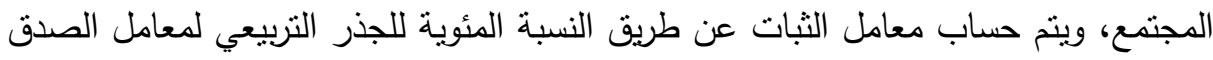

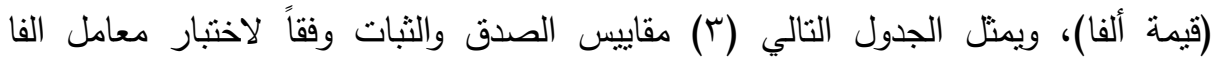
كرونباخ.

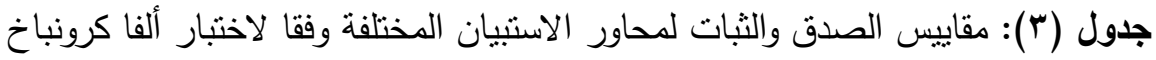

\begin{tabular}{|c|c|c|c|}
\hline الثبات & قيمة معامل (ألفا) & آرقام العبارات & محاور الاستبيان \\
\hline $10, \cdot r$ & $.6 V Y T$ & $1 \cdot-1$ & الآثار الاجتماعية \\
\hline$\Lambda \Gamma, 00$ & .6791 & $|v-1|$ & الآثار الاقتصادية \\
\hline$(\lambda 9,7)$ & $.6 \Lambda \cdot r$ & $\frac{T M-11}{K M}$ & الآثار البيأُـية \\
\hline$\Lambda \uparrow, \cdot 7$ & $\cdot, V \leq \Gamma$ & $r \mu-1$ & 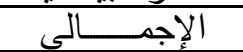 \\
\hline
\end{tabular}
جلول (؛): تحليل الارتباط والمساهمة النسبية للاثار الاجتماعية على المجتمع العراقي في

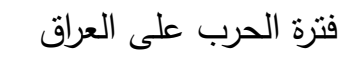

\begin{tabular}{|c|c|c|c|c|}
\hline المعنوية & 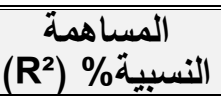 & $\begin{array}{c}\text { الارتباط (R) } \\
\text { (R) }\end{array}$ & المحور & b \\
\hline$\cdot, \cdots$ & $\Gamma V, 0 \Lambda$ & $\cdot, 7 / \pi$ & الاثار الاجتماعية & $\mathrm{X}$ \\
\hline$\cdot, \cdots$ & $T \Gamma, Y$. & $\cdot, 1 \times 90$ & فترة الحرب على العراق & $\mathrm{Y}$ \\
\hline
\end{tabular}

ويمثل الجدول السابق رقم (ع) تحليل الارتباط للمتغير المستقل (الاثار الاجتماعية)

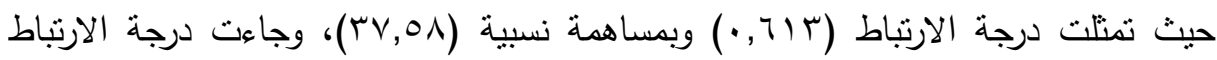

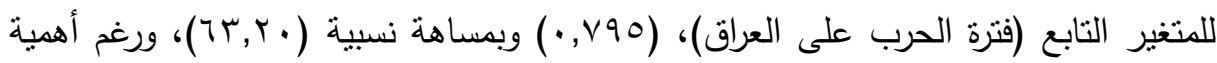

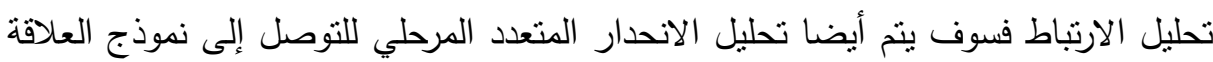
بين الاثار الاجتماعية "كمنغيرات مستقلة" وبين فترة الحرب على العراق "كمتغير تابع"، وفيما يلي يمثل الجدول النالي رقم (0) المنغيرات ذات التأثير المعنوي الايجابي طبقا لترتيب أهميتها في معادلة الانحدار المرحلي.

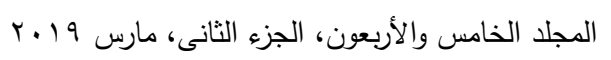


جدول (•): المتغيرات ذات التأثنر المعنوي الايجابي للآثار الاجتماعية على المجتمع العراقي

\begin{tabular}{|c|c|}
\hline نآثر أداء المعلمين وأساتذة الجامعات بالاوضاع الاجتماعية في فترات الحرب & X1-6 \\
\hline ندرة أساتذة الجامعات والمعلمين المعتمدين والمؤهلين من وزارة التعليم لتعليم & $\mathrm{X} 1-1$ \\
\hline عدم توفر التجيزات المادية اللازمة للعملية التعليمية من أماكن وكتب وأوراق & $\mathrm{X} 1-2$ \\
\hline عدم توفر المعدات الادارية المتمنلة في أجهزة الحاسوب والمطبوعات العملية & $\mathrm{X} 1-10$ \\
\hline كثرة هجرة المعلمين نتيجة للعنف والتهديد المنظم & $\mathrm{X} 1-5$ \\
\hline
\end{tabular}

ومما سبق يقتضي رفض الفرض الاول، والذي يقضى بعدم وجود علاقة ذات دلالة

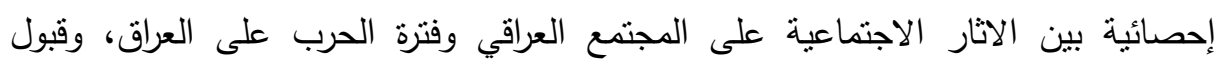

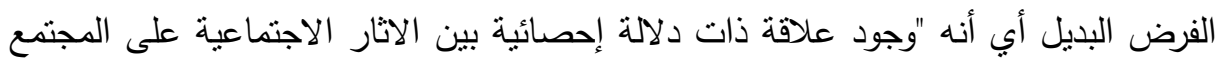

$$
\text { العراقي فى فترة الحرب على العراق". }
$$

يتمثل الفرض الثاني بأنه "لا توجد علاقة ذات دلاتلة إحصائية بين الاثار الاقتصادية

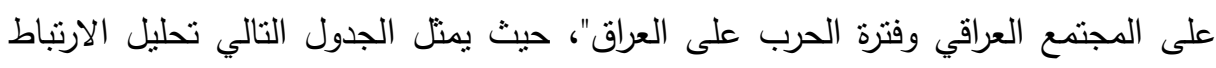
والمساهمة النسبية للاثار الاقتصادية على المجتمع العراقي وفترة الحرب على العى العراق.

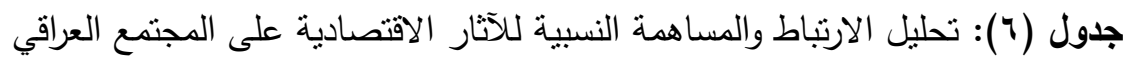

\begin{tabular}{|c|c|c|c|c|}
\hline المعنوية & 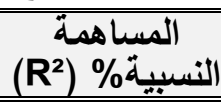 & $\begin{array}{c}\text { معامل الارتباط } \\
\text { (R) }\end{array}$ & المحــــور & r \\
\hline$\overline{e, \cdots}$ & $r 9,07$ &., $7 r q$ & الاثار الاقتصادية & $\mathrm{X} 2$ \\
\hline$\cdot, \cdots$ & $71, V V$ & $\Lambda T \cdot, V$ & فنزة الحرب على العرق & $\mathrm{Y}$ \\
\hline
\end{tabular}

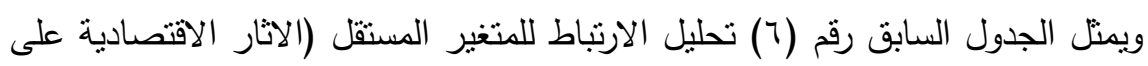

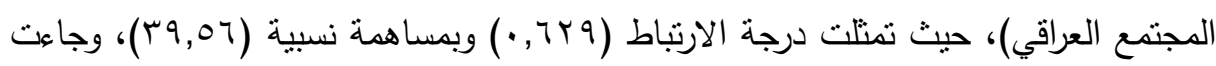

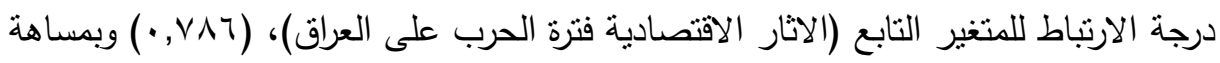

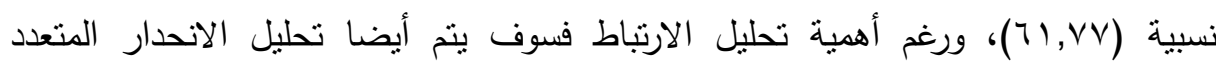

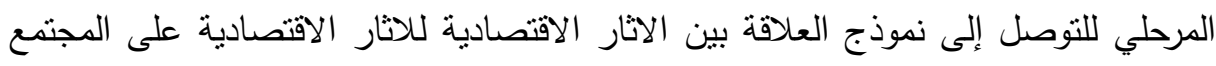

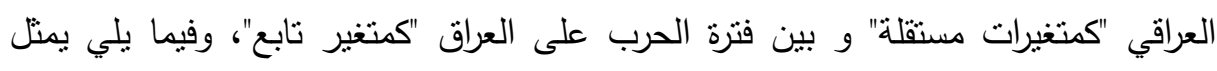

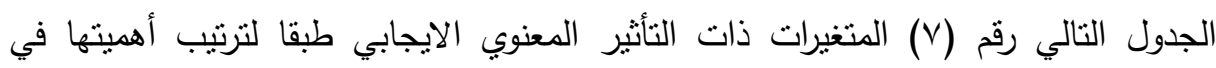

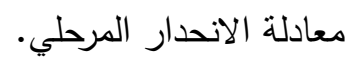


جدول (V): المتغيرات ذات التأثير المعنوي الايجابي لنطاق الأمور الرئيسية للمراجعة

\begin{tabular}{|c|c|}
\hline ارتفاع مؤشرات الفساد الاداري والمالي من تهريب ورشناوي وغسيل أموال & $\mathrm{X} 2-16$ \\
\hline تضخيم تكاليف المشاريع الاستثمارية & $\times 2-17$ \\
\hline استمرار مديونية الحكومة العراقية وارتفاع معدلات البطالة & $\times 2-13$ \\
\hline تؤثر القرارات الداخلية والخراجية على الاثر الاقتصادي للمجتمع العراقي & $\mathrm{X} 2-11$ \\
\hline
\end{tabular}

ومما سبق يقتضي رفض الفرض الثاني، والذي يقضى بعدم وجود علاقة ذات دلالة

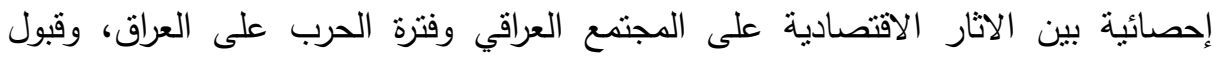

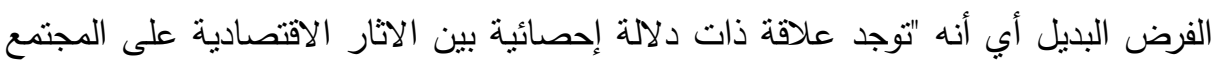

$$
\text { العراقي وفنزة الحرب على العراق". }
$$

ينص الفرض الثالث بأنه "لا توجد علاقة ذات دلالة إحصائية بين الاثار البيئية على وفرة المجتمع العراقي وفترة الحرب على العراق"، ويوضح الجدول التالي رقم (^) تحليل الارتباط والمساهمة النسبية للاثار البيئية على المجتمع العراقي وفترة الحرب على العراق.

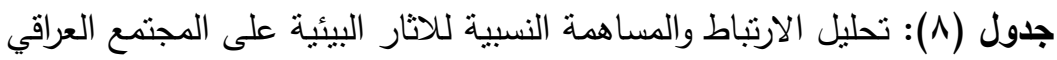

\begin{tabular}{|c|c|c|c|c|}
\hline المعنوية & 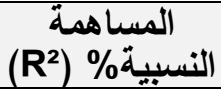 & 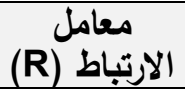 & المحــــور & r \\
\hline,$+ \cdots$ & $\varepsilon V, 19$ & $\cdot, 7 \wedge \mathrm{V}$ & الاثار البيئية & $\overline{\mathrm{X} 3}$ \\
\hline$\cdot, \cdots$ & $1 . .07$ & $\cdot, v \leqslant 9$ & فترة الحرب على العرق & $\mathrm{Y}$ \\
\hline
\end{tabular}

ويمثل الجدول السابق رقم (^) تحليل الارتباط للمتغير المستقل (الاثار البيئية على اله

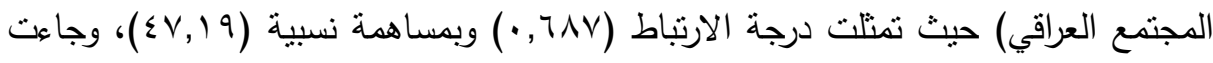

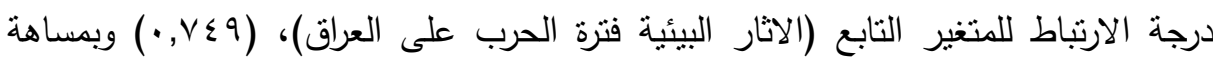
نسبية (• (. (07)، ورغم أهمية تحليل الارتباط فسوف يتم أيضا تحليل الانحدار المتعدد

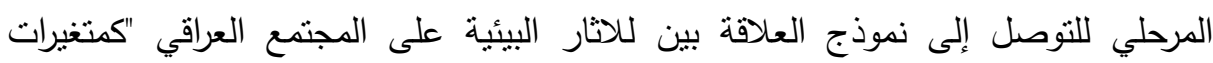

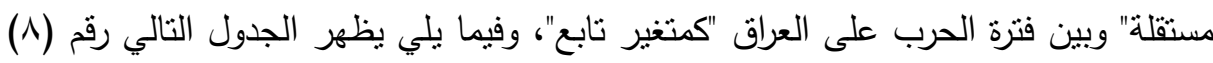

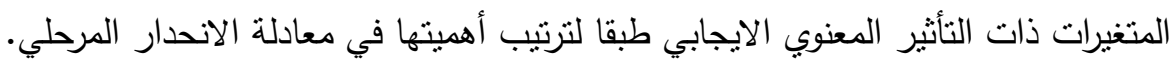




\begin{tabular}{|c|c|}
\hline اثر قرار اتمام مشروع النهر الثالث بالسلب على المجتمع العراقي & X3-18 \\
\hline آلحقت اضرار جسيمة بالبينة التحتية من مصافي النفط ومولدات الطاقة & X3-19 \\
\hline كثرة المناطق الملوثة بالالغام وبقايا متفجرات الحرب & X3-22 \\
\hline
\end{tabular}

مما سبق يقتي رفض الفرض الثالث، والذي يقضى بعدم وجود علاقة ذات دلالة

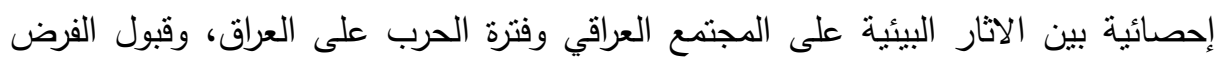

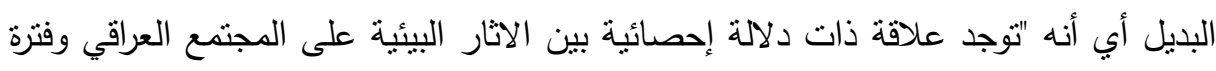

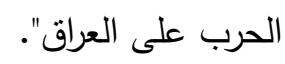

\section{المندائم}

أوضحت الدراسة التحليلية وجود العديد من الآثار الإجتماعية والإقتصادية والبيئية للحروب على العراق خلال فترة الدراسة، يمكن للباحثة اجمال أهمها على النحو التالى: الآلى الآثار الإجتماعية:

() أصبح العراق مركز الفقر والبطالة والدعارة وخطف وبيع الأطفال والأيتام والإتجار

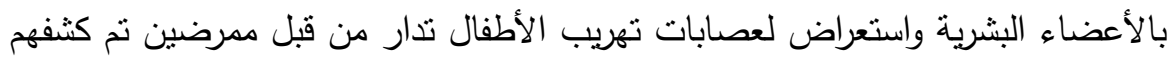
في أكثر من مستشفى حكومي.

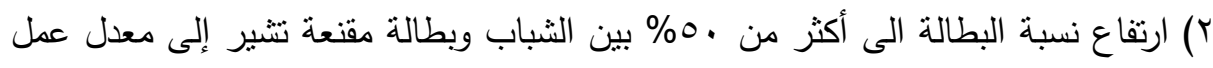

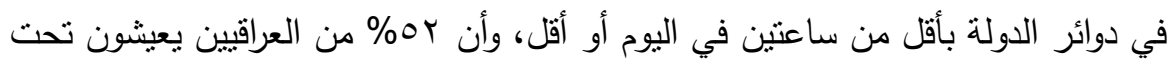

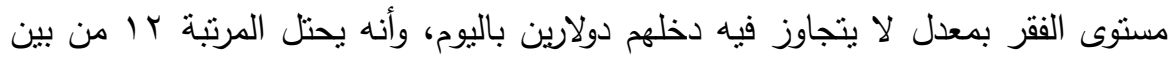
17 دولة عربية بالمنطقة من حيث الوضع الاقتصادي بالرغم من ثروته النفطية الهائلة.

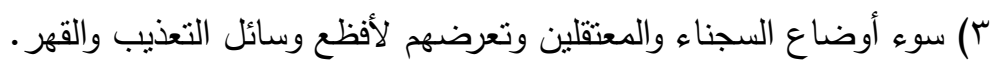
ء) فقدان الثقة بالمجتمع واختراق واستهداف منظومة القيم والأخلاق بالمجتمع العراقى. 
0) انسلاخ الفرد أو المواطن العراقي عن دولته ومن ثم مواطنته ومجتمعه وذللك على خلفية

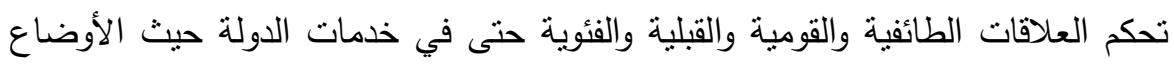

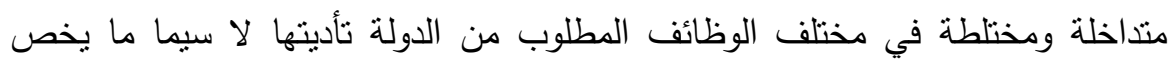

الخدمة العامة.

7) غياب الترابط الاجتماعي في المنطقة الواحدة، وأهمها التقاليد القائمة على قيم اجتماعية تشيع التآلف والتآزر بين الناس تكاد تتلاشى بعد مرور سنوات من الاحتلال على خلفية

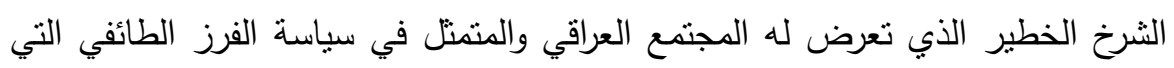

$$
\text { أسس لها الاحتلال وعززتها الأحزاب الطائفية. }
$$

الآثار الإقتصادية:

( ) تصدر العراق قائمة الدول “الأكثر تضرراً” بالعالم من الحروب والإرهاب على الصعيدين

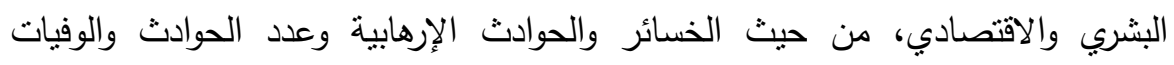

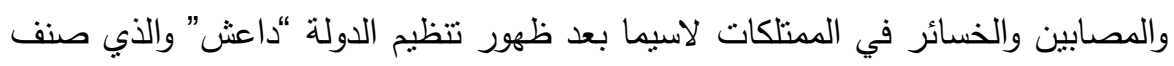
بأنه “الأكثر دموية” بين باقي التنظيمات الإرهابية.

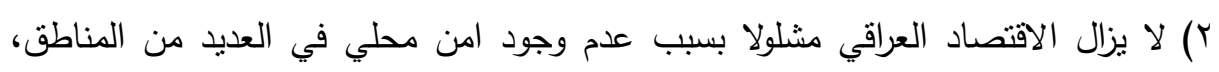
ويمتلك مستوى من الفساد يصل إلى درجة وضعته منظمة الثنفافية الدولية في المرتبة

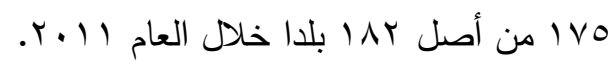
r) فثل العراق في الوصول إلى صيغة لإنجاح الاستثمار الفعال، الضرائب، وقوانين الملكية

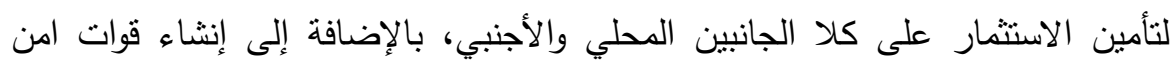
فعالة لحماية بنيتها التحتية وشركاتها.

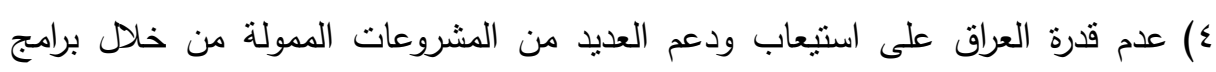

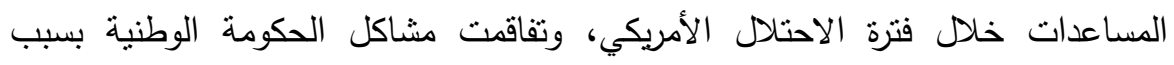
الفساد، والاقتتال السياسي، والصراعات الطائفية والعرقية على الصعيدين الإقليمي والمحلي. 


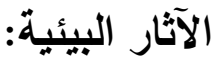

() تملح الأراضي: تعتبر مشكلة تملح الأراضي الزراعية في العراق من المشاكل الرئيسية

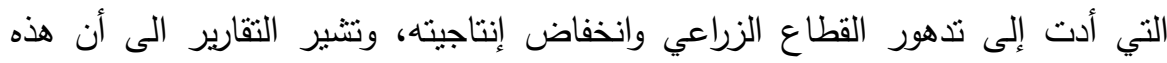

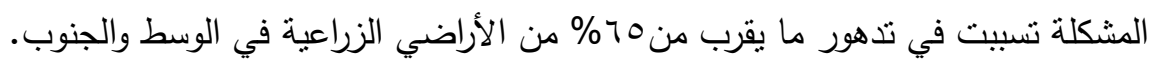

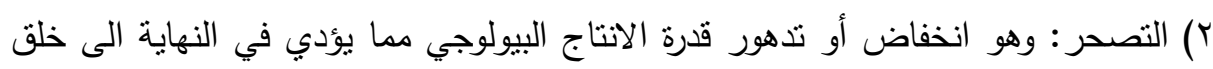

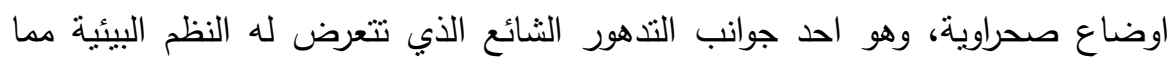

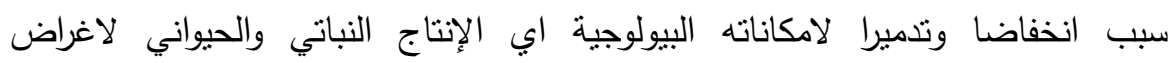

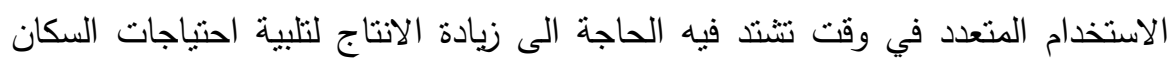
الذين بتزايدون باستمرار وينطلعون لتحقيق التنمية السليمة.

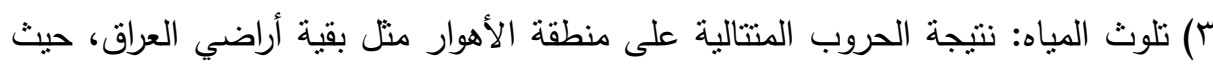

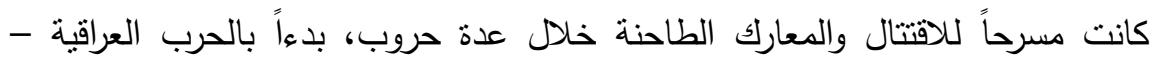

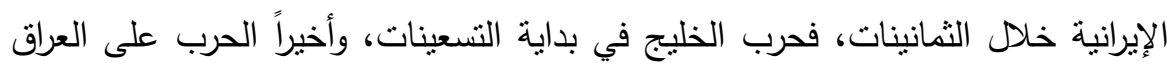

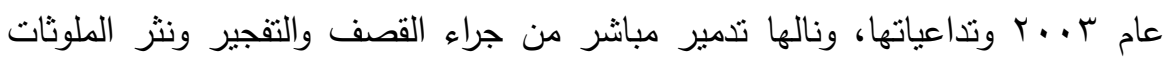
والنفايات.

ع) نلوث التربة: شهدت البيئة العراقية والتربة على وجه الخصوص ثلاثة حروب كارثية

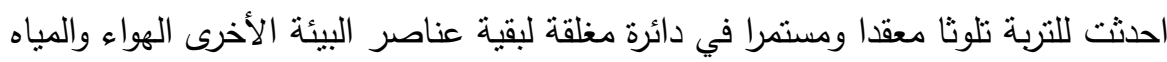

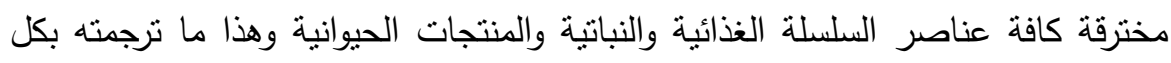
وضوح التدهور الكارثي للحالة الصحية المروعة للإنسان العراقي الهنتلة بظهور الأمراض

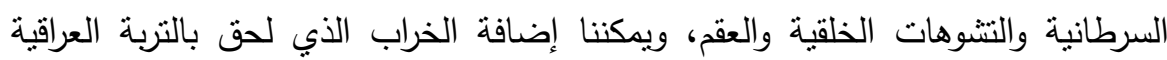

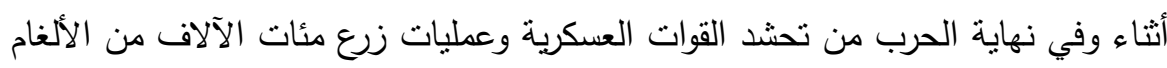
وقطع الأتجار وتدمير الغابات في كردستان العراق والنخيل في جنوب العرات العراق.

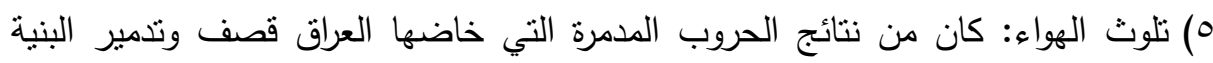

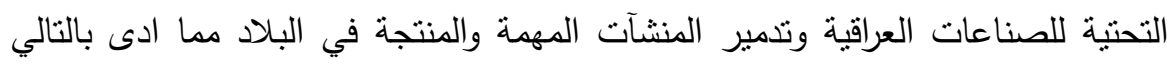

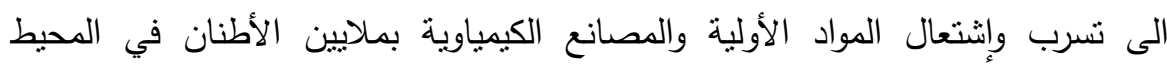
الهوائي القريب من هذه الصناعات والمنشآت.

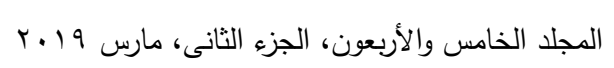


7) تلوث صحراء الخليج: إحراق آبار النفط ادى الى حدوث كارثة بيئية ادى الى تتكيل بحيرات نفطية فى الصحراء، كم تسببت الحرب بتفكل التربة الناتج عن حفر الخنادق وزرع التهاء

\section{الميوكياته}

1-العمل على نشر ثقافة السلام فى المجتمع الدولى وخاصة مناطق الحروب المشتعلة فى منطقة الثرق الأوسط للحد من وطأة الآثار السلبية للحروب. r-دعم الجهود الدبلوماسية فى حل المشاكل الطائفية والنزاعات العرقية التى تؤجج النزاع والخلاف بين الأقاليم والقبليات والعثائر العراقية. r-تعزيز سياسة الإحتواء بين دول الجوار لوأد أى خلاف عسكرى قد يحدث.

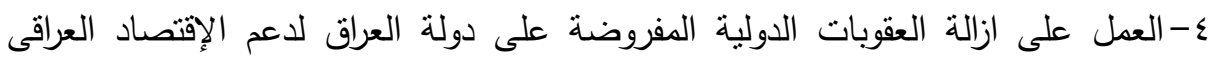
وتحريره من القيود المفروضة عليه.

ه-تشجيع المجتمع الدولى على الإستثمار فى العراق وانشاء مشروعات جديدة وخاصة أنه العراق منطقة غنية بالثروات الطبيعية.

1-تكاتق الهيئات الدولية على حل المشكلات البيئية التى حلت بالمجتمع العراقى نتيجة

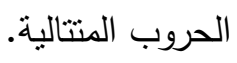

\section{zall}

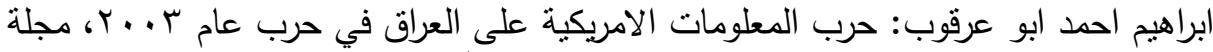

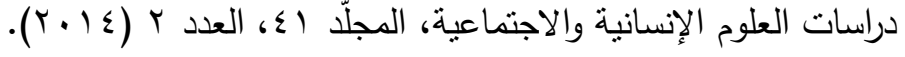

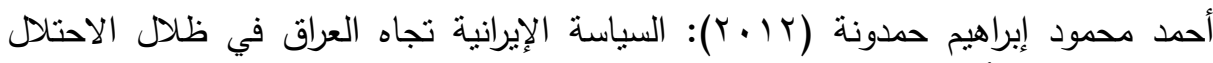

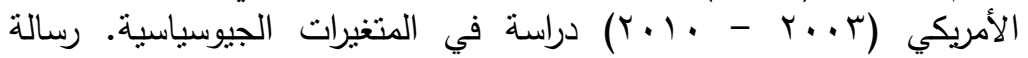

ماجستير غير منشورة، جامعة الأزهر - غزة، كليةالآداب والعلوم الإنسانية.

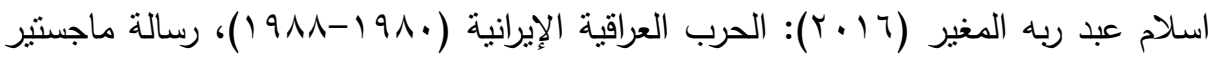
غير منشورة، الجامعة الإسلامية بغزة، كلية الآداب. 
حسن العطار (1) • †): آثار الحروب والنزاعات الاهلية على المجتمعات العربية، صنعاء.

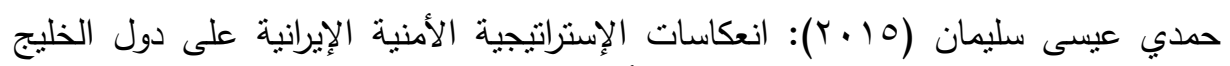

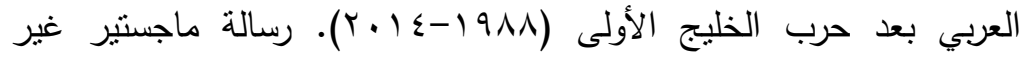

منشورة، جامعة قاصدي مرباح ورقلة، كلية الحقوق والعلوم السياسية.

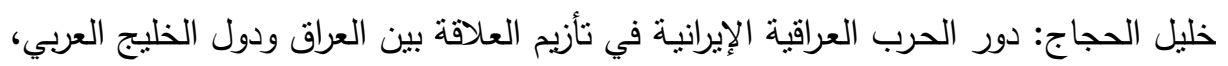

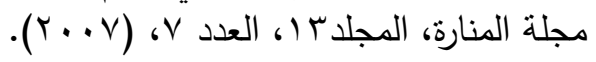

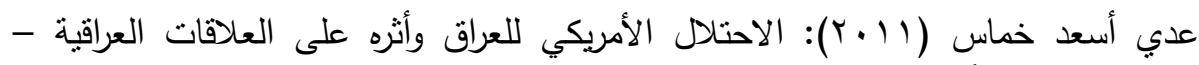

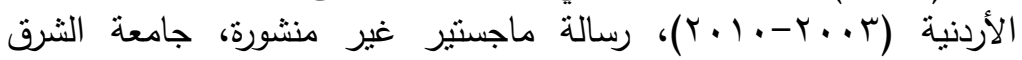

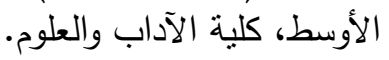

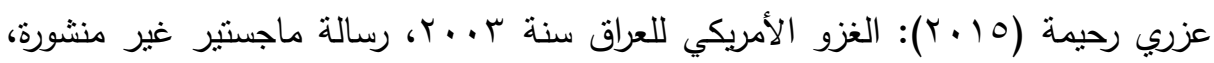
جامعة محمد خيضر بسكرة، كلية العلوم الانسانية والاجتماعية.

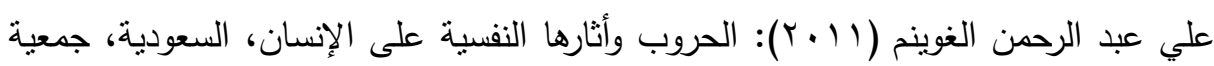

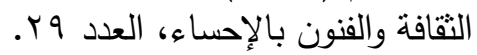

Charles and others (2007): WAR AT ANY PRICE? The Total Economic Costs of the War Beyond the Federal Budget, Joint Economic Committee, November.

Dan Morse (2011): Iraqi vice president denies involvement in terrorism, Washington Post, December 20, 2011; Associated Press, Iraqi PM urges Kurdish authorities to hand over Sunni VP, says he must face justice, December 20 | Updated: Wednesday, December 21, 5:42 AM; Michael S. Schmidt and Tim Arango, Vice President of Iraq Voices Sunnis' Anger as He Denies Ordering Killings, New York Times, December 20.

Dean Baker (2009): The Economic Impact of the Iraq War and Higher Military Spending, Center for Economic and Policy Research, NW, Suite 400.

Nasir Ahmed Al Samaraie (2007): Humanitarian implications of the wars in Iraq, international Review, Vol. 89 No. 868 Dec.

$$
\text { المجلد الخامس والأربعون، الجزء الثانى، مارس } 19 \text { ـ ا ب }
$$


Victor W. Sidel, Barry S. Levy, and Jonathan E. Slutzman (2009): Prevention of War and Its Environmental Consequences, Springer-Verlag Berlin Heidelberg.

Youssef Bassil (2012): The 2003 Iraq War: Operations, Causes, and Consequences,Journal Of Humanities And Social Science (JHSS), Volume 4, Issue 5 (Nov. - Dec).

\title{
THE SOCIAL, ECONOMIC AND ENVIRONMENTAL EFFECTS RESULTED IN WARS IN IRAQI IN THE TIME DURATION (1980 - 2015)
}

\section{Genan S. Al-Rawe ${ }^{(1)}$; Amal Abdel Hameed ${ }^{(2)}$; Nermin Ma'rouf $^{(3)}$ and Abeer Abdel Hakam ${ }^{(4)}$}

1) Post Grad., Institute of Environmental Studies \& Research, Ain Shams University 2) Faculty of Women, Ain Shams University 3) Faculty of Commerce, Al-Salmania University, Iraq 4) Faculty of Commerce, Ain Shams University

\begin{abstract}
The current study objective is crystallized in identifying the social, economic, and environmental effects produced by successive wars on state of Iraq during the Gulf War I and the Gulf War II and finally the American invasion. The study counts on the descriptive-historical method.

The researcher uses for evaluating the study sample the random class sample, distributing (185) questionnaire formsand retrieved (181) forms $(97.8 \%)$ of the distributed forms. The data collection tool for obtaining the primary data of study is represented in the questionnaire form that is designed to contain specific phrases built on the scales set by the researchers in the research field.
\end{abstract}

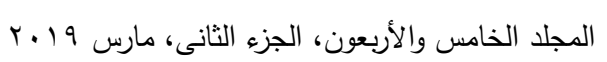


The researcher has distributed the questionnaire on study sample's items, replying their inquiries, collecting, unloaded and coded the data.

The study comes to several findings including: there are several negative impacts of successive wars on Iraq represented in the social impacts which on top that (Iraq has become a center for poverty, unemployment,whoredom, kidnapping and selling children, human organs trade, showoff place for gangs of children trade and smuggling, and higher up of the unemployment ratio that has reached more than $50 \%$ among youth, in addition to absence of social connections in the one area, loss of confidence among society individuals, penetration of the values and morals system in the Iraqi society).Moreover, the economic negative impacts are crystallized in the almost general paralysis in Iraqi economy because of the diffused corruption in the Iraqi government and its incapability to fulfill needs, or attract the foreign investment and benefit from economic aids programs granted to it. Added to that, the huge destruction the wars have left behind that has destroyed also the infrastructure of Iraq and damaged lots of institutions and economic establishments. Finally, the environmental effects are reflected in land salinity - desertification phenomenon - water pollution - soil air pollution - forming oil lakes in the desert, soil dissolution resulted in digging ditches and mine laying.

The study recommends the following: Working on prevailing peacefulness culture in the international community, particularly, war zones in the Middle east. Support diplomatic efforts for solving racial conflicts. Encouraging the international community to invest in Iraq. Working on removal of international penalties imposed on Iraq for supporting andliberalize Iraqi economy. 